\title{
Study on Stability and Reliability of NOx Ultra-low emission in Coal-fired Power Plants in China
}

\author{
Yang Zhang ${ }^{1,2^{*}}$, Xiaoying Xin ${ }^{1}$, Da $\mathrm{Hu}^{1}$, Wentao Zhu ${ }^{1}$, Yue Zhu ${ }^{1}$ \\ ${ }^{1}$ Huadian Electric Power Research Institute Co. Ltd., Hangzhou 310030, China \\ ${ }^{2}$ State Key Laboratory of Clean Energy Utilization, Zhejiang University, Hangzhou 310027, China
}

\begin{abstract}
Along with the rapid progress of flue gas ultra-low emission reconstruction in coal-fired power plants in recent years, the stability and reliability problems in the operation of the project have emerged, among which the denitrification problem is the most acute. Given the present situation of the NOx ultra-low emission in coal-fired power plants, several typical problems about stability and reliability have been analyzed and discussed, including flow fields uniformity, low load denitrification, in-line meter accuracy, catalyst life on the basis of extensive and thorough investigation. Relevant guidance and countermeasures are proposed to provide further reference for the following denitrification projects and operations.
\end{abstract}

\section{Introduction}

In recent years, the transformation of ultra-low emission of coal-fired power plants in China has made a rapid progress. With the development of operation and maintenance work after the transformation and the accumulation of operation and maintenance experience, the flue gas pollutant treatment has been significantly improved, and the number and duration of unplanned outage and excessive standard emissions have decreased year by year. However, under the influence of unit load, design margin, standby equipment, operation and maintenance, and other factors, there are still many problems in stability and reliability when meeting the emission requirements[1], especially NOx ultra-low emission operation.

In view of the current status of ultra-low emission of NOx in coal-fired power plants, the widely used SCR denitrification technology was taken as the key research object, extensive and thorough investigation and research on the application of key technologies were conducted. The results show that the main problems in the operation of denitrification unit are low denitrification efficiency, excessive NOx emission, excessive ammonia consumption, excessive ammonia escape concentration, increased air preheater resistance, large pressure difference in the denitrification unit, dust accumulated abrasion of the catalyst, and inoperable at a low load. Given the present situation of the NOx ultra-low emission in coal-fired power plants, several typical problems about stability and reliability have been analyzed and discussed, including flow fields uniformity, low load denitrification, in-line meter accuracy, catalyst life on the basis of extensive and thorough investigation. Relevant guidance and countermeasures are proposed to provide further reference for subsquent denitrification projects and operations.

\section{Flow Fields Uniformity}

The flow field problem is the core problem of the whole denitration plant construction, operation and maintenance. At present, the problems encountered in actual SCR denitrification operation, such as the denitrification efficiency failing to reach the design value, excessive ammonia escape concentration, and ash accumulation and wear of the catalyst, are often caused by uneven distribution of the flow field. Temperature field, velocity field and concentration field, as three key characterization parameters of the flow field, determine the comprehensive performance of the denitrification unit. For example, the uneven temperature field of the same section leads to the uneven denitrification performance of the catalyst. Non-uniform velocity field leads to inconsistent residence time of flue gas, which will cause ash accumulation, clogging and wear in the denitrification reactor, thus affecting the performance of the denitrification device. The uneven concentration field will lead to the deviation of ammonia nitrogen distribution in the denitrification reactor which will bring about excessive ammonia escape and cause damage to the air preheater and other downstream equipment.

For the design of denitrification unit, it is extremely important to take appropriate measures to ensure the uniformity of flue gas velocity and reactant distribution at catalyst inlet section[2]. In the design stage of denitrification engineering, numerical flow field simulation and physical model test studies are generally adopted to ensure the flow field at the catalyst inlet section and the uniformity of ammonia injection mixture in the denitrification reactor through the arrangement of ammonia injection mixing device and the setting of flow

Corresponding author: cola1860@163.com 
deflector[3]. However, due to the limited reconstruction space, compact flue layout, large changes in flue section and many sharp turns, the actual project operation effect is often not ideal. When NOx emission is limited to $50 \mathrm{mg} / \mathrm{m}^{3}$ as required by the ultra-low emission, the problem of flow field uniformity becomes more prominent[4]. Even if the engineering design is relatively reasonable, the problem of flow field will occur in actual operation due to the change of boiler combustion status, the change of flow field components in denitration reactor or the change of regulating performance of ammonia injection valve. It often leads to the increase of ammonia escape concentration and the obvious aggravation of air preheater blockage. At present, the air preheater resistance of some units has reached to more than $2000 \mathrm{~Pa}$, and even some units have to reduce the load operation due to insufficient fan output. Some units with high flue gas temperature even have $\mathrm{NH}_{4} \mathrm{HSO}_{4}$ sticking on the pole line of the ESP plate and the draft fan blade. As shown in Figure 1, ESP polar sticky dirty after denitration reconstruction at a typical $300 \mathrm{MW}$ "W" flame boiler, ash composition analysis results showed that except the $\mathrm{Al}_{2} \mathrm{O}_{3}, \mathrm{SiO}_{2}, \mathrm{Fe}_{2} \mathrm{O}_{3}$ for conventional coal-fired fly ash components, it also contains a large amount of $\mathrm{SO}_{3}$. This finding is closely related to the use of the high-sulfur coal, abnormal SCR denitration operation, and the ammonia consumption that has significantly exceeded design value.

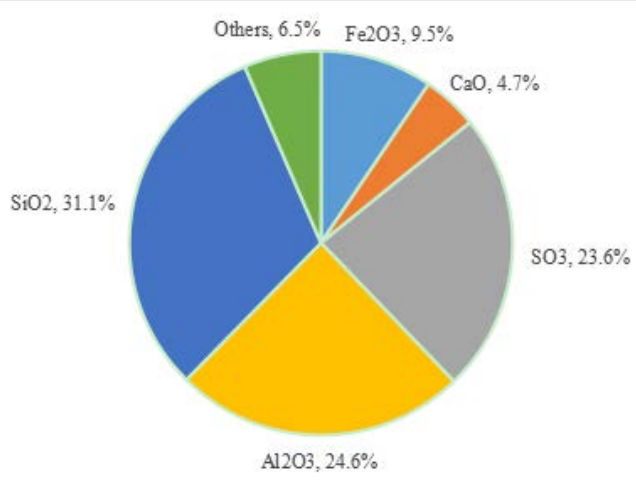

Fig.1. Composition analysis results of ash on the electrostatic precipitator at a specific $300 \mathrm{MW}$ unit.

Aimed at the problem of non-uniform flow field, boiler combustion optimization and tuning of denitration spraying ammonia test should be periodically carried out, guarantee the stability of the flow field in the SCR reactor. At the same time, it should also pay attention to the ammonia dampers, ammonia injection nozzle and other denitration equipment maintenance, so that the denitration device is efficient, stable and safe operation for a long time. When the inhomogeneity of the flow field is mild, the flow field in the denitrification reactor can be adjusted through field adjustment test to meet the operation requirements. As shown in Figure 2, the NOx concentration distribution at the reactor outlet is significantly improved after the optimal test of ammonia injection, which is more conducive to control the ammonia injection amount and ammonia escape concentration. However, when the flow field changes greatly or the design of denitrification device is not reasonable, the flow field problem cannot be eliminated simply through optimization test. In this case, it is necessary to carry out optimization and transformation of the flow field to solve the problem thoroughly.
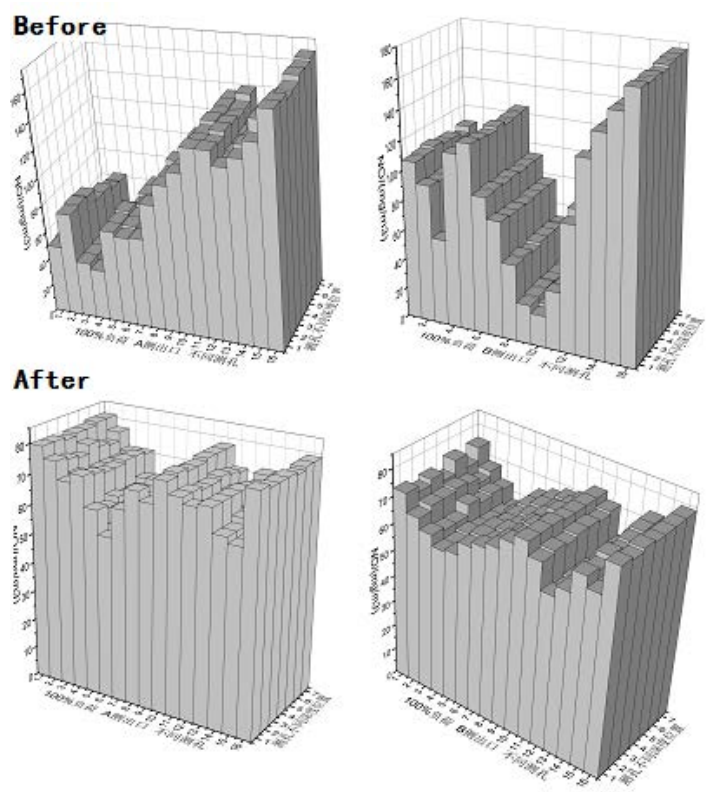

Fig.2. NOx concentration distribution before and after ammonia injection optimization test at a specific SCR denitrification facility.

\section{Low-load Operation}

At present, the contradiction between power supply and demand is increasingly serious in China. The unit load reduction and frequent peak adjustment happen frequently, which results in growing denitrification at low load operation. Before the transformation of ultra-low emission, the flue gas temperature at the outlet of the economizer under low-load conditions in some power plants was too low to meet the minimum continuous operation temperature of the catalyst, leading to the failure of the system in normal operation[3]. However, the minimum continuous operation temperature of the catalyst is determined by the concentrations of $\mathrm{SO}_{3}$ and $\mathrm{NH}_{3}$ in the flue gas. Due to the increase in the amount of ammonia injection required by ultra-low emission, the $\mathrm{NH}_{3}$ concentration in the flue gas increases significantly, which further increases the minimum continuous operation temperature of the catalyst, and aggravates the problem of low-load denitrification operation. On the other hand, the environmental protection departments have not lowered their requirements for the above environmental protection indicators under abnormal working conditions, and some local governments have put forward explicit requirements for the depth peak regulation, wide load denitrification, standard discharge assessment, electricity price assessment and other aspects, thus posing great challenges to the operation stability of the denitrification system. As shown in Figure 3, based on the statistical results on 193 units NOx excessive emissions in 2017, the excess emissions caused by the insufficient of temperature at low load reached $11 \%$ and 
$14 \%$ respectively for number and time, which indicates abnormal denitration operation at low load has become an important factor affecting the stability of denitrification operation.

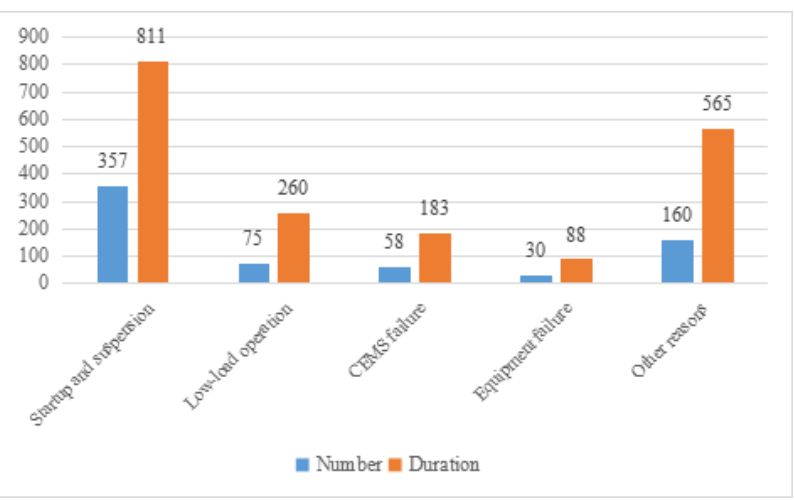

Fig.3. The reasons statistical result of NOx excessive emission

Based on the demand for wide load denitrification, some power generation enterprises have made active exploration in operation adjustment and achieved certain results[5]. The adjustment means mainly include boiler combustion adjustment, SCR operation mode adjustment and denitration operation control. Boiler combustion adjustment mainly covers the adjustment of the boiler air volume, the proportion of air distribution, burner Angle, coal mill operation level, coal mill outlet temperature, boiler long blowing, reheater side flue gas baffle degree and other means to improve flue gas temperature of the coal economizer outlet.The adjustment of SCR operation mode mainly include the efficient operation of the denitrification unit through the adjustment and optimization of ammonia injection. The formation concentration of $\mathrm{NOx}$ is minimized through the optimization of low-NOx combustion, so as to reduce the amount of ammonia injection and increase the minimum continuous operation temperature of the denitrification catalyst. Denitration operation control mainly lies in reducing the flue gas temperature limit of SCR exits on the basis of accurate verification on catalyst ABS (a lot of $\mathrm{NH}_{4} \mathrm{HSO}_{4}$ could be generated at this temperature), MIT (minimum ammonia injection temperature), MOT (minimum continuous operation temperature), and coordinating control unit load allocation and denitration operation on the basis of the analysis of the regularity of $\mathrm{NH}_{4} \mathrm{HSO}_{4}$ deposit and decomposition under specific flue gas conditions. In general, for projects with small flue gas temperature deviation from design value and large possibility to achieve low-load operation through optimized operation adjustment, factors affecting low-load operation of SCR should be comprehensively considered to form a feasible low-load operation mode to avoid large-scale transformation.

Current industry low-load denitration technology including economizer flue gas bypass, economizer feedwater bypass, economizer grading, hot water recirculation and so on, but the application of various technical measures all have certain boundary conditions, the investment and the impact on the running efficiency are different, so all items should be based on actual situation, comprehensive analysis of boundary conditions, in-depth analysis of the feasibility, applicability and economical efficiency of the retrofit scheme. The most optimal technical solutions should be selected after technical and economic comparisons. In particular, the retrofit project should adopt the most appropriate scheme according to the characteristics of the units in service, the condition of coal burning, the design parameters of SCR flue gas denitration system, the condition of equipment and the layout. In general, for units with small capacity and limited annual utilization hours, wide load denitrification technology with small amount of reforming works such as economizer flue gas bypass can be considered, while for units with large capacity and higher requirements for operation economy and reliability, priority should be given to technologies like economizer grading transformation.

\section{On-line Instrument Accuracy}

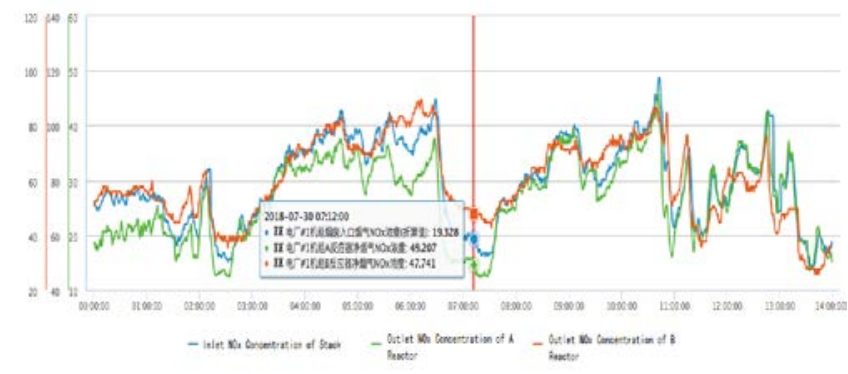

Fig.4. Inversion phenomenon of NOx monitoring result on a specific $600 \mathrm{MW}$ power unit

The NOx and $\mathrm{NH}_{3}$ measuring instruments at the outlet of SCR denitrification reactor are the two most important instruments in the denitrification equipment. However, in the current practical operation, measurement results are often not representative due to limited instrument layout points, large variation range of boiler load and poor flow field[6]. As shown in Figure 4, the concentration of NOx at the SCR denitrification outlet is more than 2 times higher than that at the chimney inlet, which is a typical manifestation of unrepresentative $\mathrm{NOx}$ measurement points. On the other hand, the current SCR denitrification device requires that ammonia escape concentration below $3 \mathrm{ppm}$. However, due to the harsh environment of flue gas, measurement technology limitations, and error transmission of sampling, analysis, calibration, data transmission and other aspects, the monitoring results of ammonia escape meter are generally inaccurate, which cannot play a guiding role in the operation of denitrification facilities[7]. As shown in Figure 5, 180 sets of ammonia escape meter running status show that 46 units of equipment have high failure rate, and another 8 units can not operate normally, that is to say, the abnormal operating unit accounted for $30 \%$, and the other $70 \%$ that can run normally is subject to data accuracy verification. 


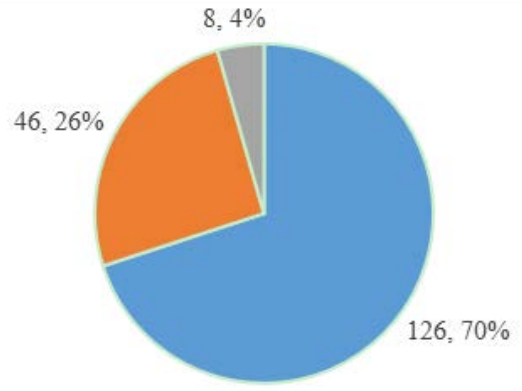

= Normal Running $\mathbf{n}$ High Failure Rate $\mathbf{m}$ Out of Order

Fig.5. Running state statistical result of ammonia slip online monitoring device

In view of the lack of representativeness of the monitoring results of NOx meter at the outlet of the denitrification reactor, on the one hand, the actual operation should still be controlled according to the NOx concentration value at the chimney inlet considering that the NOx concentration field at the chimney inlet is generally uniform after "rectifying" by dust remover, desulfurization and other equipment. On the other hand, the assessment and optimization of the flow field in the denitrification reactor should be entrusted to the testing unit as soon as possible to ensure the uniformity of NOx concentration field at the reactor outlet. If necessary, the online instrument sampling points should be rearranged according to the grid test results to ensure the representativeness of the NOx online monitoring point. In addition, some power generation enterprises can effectively solve the problem of sampling representativeness by setting multi-point sampling devices and conducting mixed measurement.

In view of the above problems of the reliability of ammonia escape meter and the accuracy of monitoring results, power generation enterprises should strengthen the maintenance of monitoring instruments to ensure that the monitoring instruments can reflect the variation trend of ammonia escape. At the same time, the ammonia escape situation can be comprehensively determined by overall consideration of the online parameter changes of outlet NOx concentration, ammonia consumption and air preheater pressure difference. If conditions permit, the regular monitoring of ammonia content in fly ash by ion chromatography (DL/T 1494-2016) can be referred to judge the change of ammonia escape.

\section{Catalyst Life}

The denitration efficiency requirements are higher than $85 \%$ generally after ultra-low emission reconstruction, requirements on flow field uniformity and catalyst performance stability further improve. The catalyst quality problem, fly ash block and wear, flow field inhomogeneity bring about a large number of catalyst replacement needs, which generally fail to meet the designed chemical life[8]. In addition, although the ultra-low emission standard requires the nitrogen oxide emission concentration to be controlled below $50 \mathrm{mg} / \mathrm{m}^{3}$, in actual operation, most power plants generally control the emission at about $30 \mathrm{mg} / \mathrm{m}^{3}$ to avoid system fluctuation and exceed the standard, further shortening the service life of the catalyst. As shown in Figure 6, the statistical results of seven ultra-low emission units with the need to replace catalysts show that the actual service life of all units is shorter than the chemical life guaranteed by performance, and the shortest actual service life is only $44 \%$ of the guaranteed performance life.

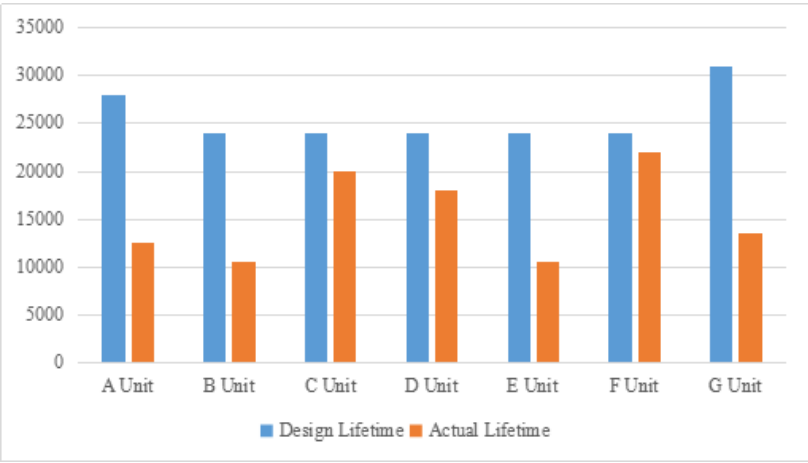

Fig.6. Service life statistical result of the proposed replacement catalyst

In denitration project design and selection design of catalyst, catalyst performance and life expectancy is designed according to the boundary conditions and the performance guarantee values. In the actual operation, the service life of catalyst is affected by the factors such as the coal and the unit operation condition which often deviates from the design conditions. Thus, the catalyst life management work need to be adjusted according to actual situations[9]. But this work is demanding in professional equipment and personnel skills given a confluence of factors. For example, the practical denitration catalyst operation seldom requires adjustment and control of the power generation enterprise operations staff. The catalyst control is quite difficult to implement due to the concealment of the catalyst life problem. Besides, there are inaccurate measurement of ammonia escape, non-uniform flow field and other related problems. Therefore, in the process of SCR denitration operation, professional organizations should be invited to help solve the above problems, technical services of catalyst life management should be carried out.

Service contents of catalyst life management technology mainly include carrying out evaluation test, diagnosis test, optimization test, in-service catalyst performance test, catalyst life evaluation and making prediction on a regular or irregular basis. Evaluation test is implemented to know the performance status of denitrification device and identify problems in time. When there is a problem, the diagnostic test is launched to figure out the causes. To solve the problems of ammonia escape exceeding the standard and uneven flow field operation, optimization test should be carried out. The plan of catalyst addition, replacement, regeneration or disposal should be formulated based on the attenuation of catalyst activity resulting from regular catalytic performance testing and the predicted residual life of 
catalysts,obtained from the evaluation results. The denitration device operation problem can be solved through catalyst life management technology service. Corresponding prevention and solution measures are put forward to eliminate problems at an early stage, thus reducing denitration device running cost and prolonging the life of denitration catalyst so as to ensure that the denitration device to maintain safe, stable and efficient operation and reduce the environmental risk.

\section{Conclusion}

In view of the current stability and reliability problems in the ultra-low emission operation of NOx in coal-fired power plants, power generation enterprises, relevant industrial companies and technical service units should timely summarize the causes and lessons of the stability and reliability problems of denitrification devices, and form corresponding countermeasures. Power generation enterprises should strengthen the technical training of operational management, improve operations staff so as to prevent, judgment, analysis and the ability to solve the problem of denitration operation. Technical service units should provide quality and efficient technical service, discover and solve the problems timely in the operation of the denitration device and ensure the efficient operation of the denitration device. Related industry companies should provide quality products and economic and effective engineering optimization. By giving full play to the expertise of all parties, the stable, efficient and reliable operation of the NOx ultra-low emission in coal-fired power plants can be realized.

We appreciate the financial support from the National Key Research and Development Program (NO. 2017YFB0603201) and the Key Science and Technology Projects of China Huadian Group Co., Ltd. (CHDKJ17-01-55).

\section{References}

1. ZHU Yue. Key technical issues of environmental protection island of thermal power plant $[\mathrm{J}]$. Power Generation Technology, 2018, 39(1): 1-12.

2. ZHANG Yang, FENG Qianwei, PEI Yukun, et al. Study on operation\&maintenance technology of SCR denitrification from coal-fired boiler flue gas [J]. Electric Power Technology and Environmental Protection, 2016, 32(5): 32-34.

3. ZHANG Yang, YANG Yonglong, FENG Qianwei, et al. Key technical issues of SCR denitrification from coal-fired boiler flue gas [J]. Electric Power, 2015, 48(4): 32-35.

4. LI Tong. Ultra-low emission reconstruct of denitrification system based on NOx uniformity test of SCR reactor [J]. Chinese Journal of Environmental Engineering, 2018, 12(4): 1112-1119.

5. SUN Weipeng, CHEN Shaohua, JIANG Yong, et al. Full load operation practice of a denitration unit with zero retrofit on the equipment [J]. Power Equipment, 2018, 32(3): 184-187.

6. LI Qing, JIANG Long, GUO Yue, et al. Current applications and key problems of ultra-low emission for coal-fired power plant [J]. High Voltage Engineering, 2017, 43(8): 2631-2637.

7. LI Chao, ZHANG Yang, ZHU Yue. Analysis on the application status of ammonia slip online monitoring of SCR denitrification from coal-fired boiler flue gas [J]. Power Generation \& Air Condition, 2017, 38(5): 41-44.

8. DU Zhen, WANG Zhidong, YAN Min, et al. Analysis on actual operation performance of SCR denitration catalyst [J]. Electric Power, 2018, 51(2): 133-136.

9. ZHOU Jianxin, YU Cong, JIANG Xiaoming, et al. System for performance evaluation and lifetime management of SCR DeNOx catalysts in coal-fired power plants [J]. Electric Power, 2015, 48(4): 11-15. 